\title{
The Effect of Tourniquet Application on Serum Calcium and Inorganic Phosphorus Determination
}

\author{
WANKASI, MARTIN .MIEEBI.*1 AGORO, ENI-YIMINI .SOLOMON ${ }^{2}$ \\ ALABRAH, PETER.WABOTE ${ }^{3}$ Edidiong Okon Tommy ${ }^{4}$ \\ 1.Department Of Medical Laboratory Science, College of Health Science, Niger Delta University, Wilberforce \\ Island, Bayelsa State, Nigeria. \\ 2.Department of Biochemistry, Federal University, Otuoke, Ogbia, Bayelsa State. \\ 3.Department of Obstetrics and Gynaecology, Federal Medical Centre, Yenagoa, Bayelsa State, Nigeria. \\ 4.Department of Haematology and Blood Transfusion, Federal Medical Centre, Yenagoa, Nigeria
}

\begin{abstract}
Venous blood sampling is usually performed using a tourniquet to help locate and define peripheral veins to achieve successful and safe venipuncture. Despite widespread usage of tourniquets for venipuncture by phlebotomists, very few are aware of the effects of tourniquet application on laboratory parameters. This study was set out to determine the influence of different tourniquet application times on total serum calcium and phosphorus concentrations in healthy individuals. A total of hundred (100) healthy subjects were used for the study and three (3) set of venous blood samples were collected from each subjects without tourniquet application, $1 \mathrm{~min}$ and 5min after tourniquet applications respectively. Samples were collected into plain containers and allowed to clot at room temperature for 20 minutes, centrifuged and serum separated. The samples were analysed for calcium and phosphorus concentrations using WHO approved methods and standard operating system (SOP). Data obtained were analysed statistically using Two-Way Analysis of variance (ANOVA) SPSS statistical package (version 20). The result revealed a significant increase $(\mathrm{P}<0.05)$ in concentrations of total and ionized calcium in samples collected after 5 minutes of tourniquet application. The concentration of inorganic phosphate ( $\mathrm{Pi}$ ) was not affected by the application and removal of the tourniquet. This study showed that the acceptable period recommended for tourniquet application should be within 60 seconds. Therefore, if blood sample cannot be collected within 60 seconds, non-application of tourniquet should be used especially for calcium profile determination.
\end{abstract}

DOI: $10.7176 / \mathrm{JHMN} / 65-07$

Publication date: August $31^{\text {st }} 2019$

\subsection{Introduction}

Sample collection is a pre-analytical procedure that determines the accuracy of laboratory results and the aptness of therapeutic interventions. A compromised sample collection procedure inadvertently affects accurate laboratory result with an attendant wrong treatment regime. Blood is the most commonly used sample in laboratory analysis and is collected with the aid of a tourniquet.

A tourniquet is widely used during blood sampling for facilitating visualization of the vein and to perform successful venipuncture. Several studies have investigated changes in biochemical and haematological properties of venous blood at different time points following tourniquet application, but the results cannot be easily adapted to a single standard procedure ${ }^{1,2,3}$. Report from previous study conducted by Lippi et al., indicate that tourniquet application before blood sampling may affect some laboratory parameters.

Calcium is one of the most abundant mineral in the body. About 99 per cent of calcium in the body is found in the bones and teeth while the remaining $1 \%$ is non-bone calcium located in the intracellular and extracellular (blood stream and interstitial fluid) tissues. This one (1) percent plays a vital role in the human health and biochemical processes ${ }^{2}$. Calcium has a number of critical roles in physiology. It is required for muscle contraction, as an enzyme co-factor, and as a second messenger. In order for these processes to function properly, extracellular calcium concentration must be maintained within a narrow range. The bone act as a reservoir to allow serum calcium concentrations maintained optimally. However, excessive demineralization of bone can lead to severe problems in older individuals ${ }^{4}$.

Phosphorus is a major element in all plants and animals. It is present in the form of calcium phosphate in bone ${ }^{5}$. Calcium and phosphate must be deposited in bone and resorbed from bone together. Most phosphorus in the body is present as phosphate; as a result, phosphorus economy is closely related to that of calcium. Phosphate plays an important role in structural support and soft tissue. It is the major component of hydroxyapatite in bone, whereas the phosphate found in soft tissue is cellular in nature ${ }^{5}$. Although phosphate can be found in organic and inorganic forms, only concentrations of the inorganic form can be measured in the clinical laboratory. Phosphate concentrations can be measured in serum, where approximately $55 \%$ is free (ionized), $35 \%$ is complexed with small cations, and $10 \%$ is protein bound. Phosphate plays important roles in the body; organic phosphate is one of the building blocks of DNA, phospholipids, and high-energy compounds such as ATP ${ }^{6}$. 
The type and time of tourniquet application before blood is drawn has been one common source of preanalytical errors ${ }^{3}$. Although, venous blood sampling are usually performed using a tourniquet to help locate peripheral veins to achieve successful and safe venipunctures. However, very limited information is available on the effects of tourniquet application on laboratory parameters including (calcium and phosphate) and on how to use a tourniquet for blood sampling. This study is aimed at to determine the influence of different tourniquet application times on total serum calcium and phosphorus concentrations in healthy individuals in Bayelsa state.

\subsection{Materials and Methods}

\subsection{Study Area}

The study was carried out in Department of Medical Laboratory Science of the Niger Delta University, Wilberforce Island, Bayelsa state, Nigeria. Bayelsa State is located in the South-South region of Nigeria with a population of about 2 million according to the population estimation of 2010 by the National Population Commission.

\subsection{Sample Size}

The sample size of one hundred (100) subjects was validated using the G-Power Software package. The subjects were apparently healthy as indicated by the clinician attached to the facility used for the volunteers' recruitment. The volunteers consisted of fifty (50) males and fifty (50) females within an age bracket of 18-40 years.

\subsection{Ethical Consideration}

The investigational proposal was approved by the Niger Delta University Project Review Committee. All volunteers were informed of the rationale of the study, and their consents were obtained willingly.

\subsection{Sample Collection and storage}

Venous blood samples were collected under aseptic condition using venipuncture technique. Three (3) mls of blood was collected from each subject three times consecutively without tourniquet application, one minute and 5 minutes respectively after tourniquet applications. The blood samples were collected into plain containers. Samples were allowed to clot properly at room temperature for 20 minutes and clots were dislodged. Samples were then centrifuged at 3000rpm for 5minutes and the separated sera were obtained and analyzed for the selected biochemical parameters.

\subsection{Laboratory Determination}

Ion Selective Electrode (ISE) method was used for the determination of calcium concentrations. The inorganic phosphorous was estimated using Agappe reagent as reported by Tietz, ${ }^{7}$. Both methods are highly rated by the WHO for the said parameters analysis.

\subsection{Statistical Analysis}

Concentrations of analytes were expressed as mean \pm standard deviation. The data obtained were analyzed using Two-Way Analysis of variance (ANOVA) using the SPSS statistical package (version 20). The level of significance was put at equal to or less than 0.05 .

\subsection{Results}

Table1: Statistical analysis of calcium and phosphorus in serum samples collected without tourniquet and after application of tourniquet for 1 minute and 5 minutes

\begin{tabular}{lccc}
\hline $\begin{array}{l}\text { Analytes } \\
\mu \mathrm{mol} / \mathrm{l}\end{array}$ & $\begin{array}{c}\text { Without Tourniquet } \\
\text { Mean } \pm \mathrm{SD}\end{array}$ & $\begin{array}{c}\text { 1Minute Stasis } \\
\text { Mean } \pm \mathrm{SD}\end{array}$ & $\begin{array}{c}\text { 5 Minutes Stasis } \\
\text { Mean } \pm \mathrm{SD}\end{array}$ \\
\hline Total Calcium $(\mathrm{Tca})$ & $2.71 \pm 0.08$ & $2.73 \pm 0.08$ & $2.81 \pm 0.09^{*}$ \\
Ionized calcium $\left(\mathrm{Ica}^{2+}\right)$ & $1.37 \pm 0.04$ & $1.38 \pm 0.05$ & $1.44 \pm 0.05^{*}$ \\
Phosphorus (Pi) & $0.88 \pm 0.33$ & $0.84 \pm 0.42$ & $0.93 \pm 0.38$ \\
\hline
\end{tabular}

Value with (*) superscripts are significantly different from the control (No stasis) value at $\mathrm{p}<0.05$ One-way Analysis of Variance (ANOVA).

Table 1 shows that there was a statistical significant difference $(\mathrm{P}<0.05)$ between samples collected without tourniquet and those obtained after 5minutes of tourniquet application for serum calcium estimation.

Table 2: Correlation between the control, $1 \mathrm{~min}$ and $5 \mathrm{~min}$ venous stasis and the analysed parameters

\begin{tabular}{lccc}
\hline $\begin{array}{l}\text { Time } \\
\text { (Minute) }\end{array}$ & $\begin{array}{c}\text { Tca } \\
(\mu \mathrm{mol} / 1)\end{array}$ & $\begin{array}{c}\mathrm{Ica}^{2+} \\
(\mu \mathrm{mol} / \mathrm{l})\end{array}$ & $\begin{array}{c}\mathrm{Pi} \\
(\mu \mathrm{mol} / \mathrm{l})\end{array}$ \\
\hline Control vs 1-min & $\mathrm{r}=0.47 \mathrm{p}<0.05^{*}$ & $\mathrm{r}=0.47 \mathrm{p}<0.05^{*}$ & $\mathrm{r}=0.54 \mathrm{p}<0.05^{*}$ \\
Control vs 5-min & $\mathrm{r}=0.19 \mathrm{p}>0.05$ & $\mathrm{r}=0.18 \mathrm{p}>0.05$ & $\mathrm{r}=0.31 \mathrm{p}>0.05$ \\
1-min vs 5-min & $\mathrm{r}=0.29 \mathrm{p}>0.05$ & $\mathrm{r}=0.31 \mathrm{p}>0.05$ & $\mathrm{r}=0.31>\mathrm{p} 0.05$ \\
\hline
\end{tabular}


Value with $(*)$ superscripts have significant correlation at $\mathrm{p}<0.05$, while $\mathrm{r}=$ represent Pearson correlation Table 2 shows the correlation between the controls and 1 minute venous stasis of the studied parameters.

\subsection{Discussion}

Spurious changes in clinical chemistry testing arising from uncontrolled pre-analytical variables might be harmful and misleading, wasting valuable healthcare resources and leading to potential errors or delays in patient care. A suitable technique for drawing blood requires that rigorous procedural criteria are fulfilled to ensure accuracy and precision of laboratory testing.

This study revealed that samples collected after 5 minutes of tourniquet application had significantly elevated changes $(P<0.05)$ in both total and ionized calcium than those collected without tourniquet. This increase may be as a result of anaerobic glycolysis that occurs as a result of prolonged tourniquet application, resulting in an increase in plasma lactate concentrations that lead to a reduction in blood $\mathrm{pH}$ and falsely increased calcium concentration. The effect of $\mathrm{pH}$ on serum calcium concentration is basically due to a decrease in $\mathrm{pH}$ value with an attendant increase in $\mathrm{H}^{+}$which displaces $\mathrm{Ca}^{2+}$ from binding sites resulting to an increase in concentration of ionized $\mathrm{Ca}^{2+}$. This finding corroborated the findings of other authors ${ }^{8,1,9,10}$ who also reported elevated concentration of total calcium and ionized calcium following prolong application of tourniquet (venous stasis).

This study further indicated no statistically significant difference $(P>0.05)$ between samples collected without tourniquet and those obtained within the first minute after tourniquet application in all the analysed biochemical parameters. This finding is in agreement with the study conducted by Melike et al., ${ }^{11}$ which reported that serum concentrations of sodium, potassium, chloride, calcium, inorganic phosphate and magnesium were not significantly affected by temporary venous stasis (1-2minutes stasis) when using a pneumatic cuff as a model for tourniquet use during blood sampling. However, the result is at variance with the report by Renoe et al. ${ }^{10}$ and Lippi et al. ${ }^{1}$. Both reported significant increased serum concentrations at 1 minute following the application of pneumatic cuff.

Furthermore, the study also shows a significant positive correlation between control samples and 1minute stasis samples in $\mathrm{tCa}, \mathrm{Ica}^{2+}$ and Pi respectively. On the other, no significant correlation was observed at the fifth minute. This shows that values in control and 1 minute stasis samples were similar, but quite different for five minutes.

\subsection{Conclusion}

The results of this study indicated that blood sampling for the measurement of serum studied biochemical parameters concentrations can be performed with the application of a tourniquet within 1minute without any adverse effects on these measured parameters. However, clinically significant changes do occur in total and ionized calcium following prolonged application of a tourniquet. Therefore, it is strongly recommended that prolonged tourniquet application should be avoided during blood collection for the investigation of serum calcium.

\section{Conflicts of Interest \\ The authors declare no conflicts of interest regarding the publication of this paper. Sponsorship/Grant}

No sponsorship or grant obtained any individual, institution or organization.

\section{REFERENCES}

1. Lippi, G., Salvagno, G. L., Montagnana, M., Brocco, G., and Guidi, G. C. (2005). Influence of short-term venous stasis on clinical chemistry testing. Clinical Chemistry Laboratory Medicine. 43:869-873.

2. Schauss, A. (1997). Minerals and Human Health: The Rationale for Optimal and Balanced Trace Element Levels. Life Sciences Press: Tacoma, Wash., 1997.

3. Young, D. S., Bermes, E. W., and Hoverstick, D. M. (2006) Specimen collection and processing sources of biological variation In: Burtis C. A, Ashwood E. R, Burns D. E. Tietz Text Book of Clinical Chemistry and Molecular Diagnosis, 4th edition, Philadelphia, Sounders Company. 41-58.

4. Brini, M., Ottolini, D., Calì, T., and Carafoli, E. (2013). "Calcium in Health and Disease". In Sigel A, Helmut RK. Interrelations between Essential Metal Ions and Human Diseases. Metal Ions in Life Sciences. Springer. 13: 81-137.

5. Calvo, M. S., Moshfegh, A. J., and Tucker, K. L. (2014). Assessing the health impact of phosphorus in the food supply: issues and considerations. Advanced Nutrition. 5(1):104-113.

6. Risteli, J., Winter, W.E. , Kleerekoper, M. \& Risteli, L . (2012). Disorders of bone and mineral metabolism. Chapter 52; 1733-1802. In: Burtis CA Ashwood ER Bruns DE (eds). Tietz Textbook of Clinical Chemistry and Molecular Diagnostics, 5th Edn.St. Louis, MO: Elsevier.

7. Tietz, N. (1983). Clinical Guide to Laboratory Tests, W.B. Saunders Company, Philad, 384. 
8. Kirsten, Y., Renkema, R., Rene, J., Bindels, G., and Joostin, G. (2008). Calcium and phosphate homeostasis. Clinical Chemistry Laboratory Medicine. 5:57-59.

9. McMullan, A. D., Burns, J., and Paterson, C. R. (1990). Venepuncture for calcium assays: should we still avoid the tourniquet? Postgraduate Medical Journal, 66(777):547-548.

10. Renoe, B. W., McDonald, J. M., and Ladenson, J. H. (1980). The efforts of stasis with and without exercise on free alcium, various cations and related parameters. Clinical Chemistry Acta. 103:91-100.

11. Melike, C., Pinar, U., Herbert, J., Meiselman, \& Oguz, K. B. (2009). Influence of tourniquet application on venous blood sampling for serum chemistry, hematological parameters, leukocyte activation and erythrocyte mechanical properties. Clin Chem Lab Med., 47(6):769-776 